\title{
Immobilization Technology \\ Down-Selection \\ Radiation Barrier Approach
}

Leonard W. Gray and Thomas H. Gould

May 23, 1997 


\title{
DISCLAIMER
}

This document was prepared as an account of work sponsored by an agency of the United States Government. Neither the United States Government nor the University of California nor any of their employees, makes any warranty, express or implied, or assumes any legal liability or responsibility for the accuracy, completeness, or usefulness of any information, apparatus, product, or process disclosed, or represents that its use would not infringe privately owned rights. Reference herein to any specific commercial product, process, or service by trade name, trademark, manufacturer, or otherwise, does not necessarily constitute or imply its endorsement, recommendition, or favoring by the United States Government or the University of California. The views and opinions of authors expressed herein do not necessarily state or reflect those of the United States Government or the University of California, and shall not be used for advertising or product endorsement purposes.

\author{
This report has been reproduced \\ directly from the best available copy. \\ Available to DOE and DOE contractors from the \\ Office of Scientific and Technical Information \\ P.O. Box 62, Oak Ridge, TN 37831 \\ Prices available from (615) 576-8401, FTS 626-8401 \\ Available to the public from the \\ National Technical Information Service \\ U.S. Department of Commerce \\ 5285 Port Royal Rd. \\ Springfield, VA 22161
}




\section{Immobilization Technology \\ Down-Selection \\ Radiation Barrier Approach}

Leonard W. Gray and Thomas H. Gould

May 23, 1997 


\section{Acknowledgments}

Organizations that provided major contributions to the development of this report include:

- Argonne National Laboratory (ANL)

- Department of Energy (DOE)

- Lawrence Livermore National Laboratory (LLNL)

- Pacific Northwest National Laboratory (PNNL)

- Savannah River Site (SRS)

- Science Applications International Corporation (SAIC)

- TRW

- Yucca Mountain Project (YMP)

This document was co-authored or reviewed by

Name

Affiliation

Team Members:

Leonard Gray

Ananda M. Wijesinghe

S. C. Slate

John M. Plodnec

Denis Strachan

S.S. Sareen

Other Contributors:

Al Disabatino

M. L. Elliott

Diane Harrison

Mal McKibben

Lonnie Moore

Joseph M. Perez, Jr.

Tom Rankin

Henry Shaw

John D. Vienna
Chairman, LLNL

LLNL

PNNL

SRS

ANL

TRW/YMP

SAIC/LLNL

ANL

DOE/YMP

SRS

LLNL

PNNL

SRS

LLNL

PNNL 
UCRL-ID- 127320

\section{Immobilization Technology Down-Selection Radiation Barrier Approach}

\section{Introduction}

In the recently published Programmatic Environmental Impact Statement (PEIS) and Record of Decision (ROD for the Storage and Disposition of Weapons-Usable Fissile Materials (Ref. 1,2), the Department of Energy (DOE) announced its decision to pursue two alternative technologies for the disposition of weapons-usable plutonium:

(1) irradiation of plutonium as mixed-oxide fuel in existing power reactors and

(2) immobilization of plutonium into solid forms containing fission products as a radiation barrier.

During the course of assessing the numerous technology variants for immobilization as input to the PEIS/ROD process, six variants were chosen for further study (Ref. 3-9). For the ROD, DOE chose an immobilization approach that would "include the use of the can-in-canister option... for a portion of the surplus, nonpit plutonium material." In the can-in-canister approach, cans of either glass or ceramic forms containing plutonium are encapsulated within canisters of high-level waste (HLW) glass, such as those being produced in the Savannah River Site's (SRS's) Defense Waste Processing Facility (DWPF) or that would be produced at a to-be-built vitrification plant at Hanford.

Lawrence Livermore National Laboratory (LLNL), in its role as the lead laboratory for the development of the immobilization technologies, has been requested by the DOE Office of Fissile Materials Disposition (MD) to recommend the preferred immobilization technology for future implementation. In a previous report (Ref. 10), LLNL proposed a two-step decision process for DOE's selection of the immobilization technology. This report (step 1) documents the bases for LLNL's recommendation that the can-in-canister or external radiation barrier approach to immobilization be selected over the homogeneous technology options (homogeneous mixtures of plutonium and fission products in a single waste form). In the second step, glass and ceramic technologies for the can-in-canister option are being developed, tested, and evaluated to support a final technology choice for the plutonium-containing immobilization form.

\section{Summary and Recommendations}

Six immobilization technology variants, previously selected for evaluation during the PEIS/ROD process, have been evaluated with respect to the nine basic criteria for fissile materials disposition. Metrics for the criteria were developed to facilitate a comparative analysis of the technology variants (Appendix A). The six technology variants evaluated are listed in Table 1, grouped according to their radiation barrier 
approach. Information and data for the technology options were provided by limited experimental studies (for glass and ceramic forms), definitions of process flowsheets, and preliminary evaluations of facility concepts and cost (Ref. 3-9).

Table 1. Immobilization Technology Variants

\begin{tabular}{lll}
\hline \multicolumn{1}{c}{ Radiation Barrier Approach } & \multicolumn{1}{c}{ Immobilization Variants } \\
\hline \hline External barrier (can-in-canister) & 1. Glass (existing facilities) \\
Homogeneous or internal barrier & 2. Ceramic (existing facilities) \\
& 3. Glass-new facilities (Greenfield) \\
& 4. Glass-adjunct melter \\
& (existing/new facilities) \\
& 5. Ceramic-new facilities (Greenfield) \\
& 6lectrometallurgical treatment \\
& (existing/new facilities) \\
\hline
\end{tabular}

Based on the evaluation described in this report, the glass and ceramic can-incanister variants are clearly superior to the homogeneous form variants based on timeliness, higher technical viability, much lower costs, and, to a lesser extent, slightly lower environmental and health risks. Therefore, LLNL recommends that DOE pursue only the can-in-canister immobilization option in its development program.

\section{Background and Evaluation Methodology}

\section{Immobilization Alternatives}

As a result of the screening process for surplus plutonium disposition, three immobilization alternatives were considered reasonable for further study (Ref. 1). The immobilization alternatives are as follows:

- Vitrification Alternative-immobilization of $\mathrm{Pu}$ in a glass matrix with processing in a vitrification facility, then disposal in an HLW repository.

- Ceramic Immobilization Alternative-immobilization of $\mathrm{Pu}$ in a ceramic matrix with processing in a ceramic immobilization facility, then disposal in an HLW repository.

- Electrometallurgical Treatment Alternative-immobilization of $\mathrm{Pu}$ in a glass-bonded zeolite (GBZ) form in an electrometallurgical treatment facility, then disposal in an HLW repository. 


\section{Immobilization Variants}

Each of the three immobilization alternatives can be implemented in a number of ways because each alternative merely defines the generic technology approach to achieve the "Spent Fuel Standard." The six immobilization variants that were chosen for further evaluation during the PEIS/ROD process can be divided into two groups according to whether the fission product radiation barrier is external (heterogeneous) or internal (homogeneous) to the plutonium-bearing form. Depending on the technology variant, plutonium is incorporated into the structure of one of three solid materials: glass (vitrification), multiple-phase crystalline ceramic, or a composite glass-bonded zeolite (electrometallurgical treatment). These immobilization variants are briefly described below:

1. Vitrification Can-in-Canister-a two-step immobilization process in which plutonium oxide is vitrified and packaged in cans containing $\leq 25 \mathrm{~kg}$ of glass. These cans are subsequently encapsulated within glass containing HLW in a large canister providing the desired radiation barrier (e.g., in the DWPF at Savannah River or a new vitrification facility at Hanford). The canisters of immobilized plutonium and fission products are subsequently stored on-site until their final disposal in the federal HLW repository (this applies also to the following five variants).

2. Ceramic Can-in-Canister-also a two-step process in which plutonium oxide is blended with ceramic precursors and then cold-pressed and sintered to form pellets of a mineral-like material. These pellets are then stacked into long tubes [similar to mixed oxide (MOX) fuel elements] and the tubes subsequently encapsulated within an HLW glass canister, similar to the vitrification can-incanister variant.

3. Greenfield Vitrification-a two-step vitrification process carried out in new facilities in which $\mathrm{Pu}$ and ${ }^{137} \mathrm{Cs}$ (source of the radiation barrier) are homogeneously distributed throughout the final glass product. Plutonium oxide is first vitrified with borosilicate glass frit (containing neutron absorbers) in geometrically favorable melters (for criticality control) without the highly radioactive ${ }^{137} \mathrm{Cs}$. This $\mathrm{Pu}$-glass frit is then remelted with additional glass frit (also containing neutron absorbers) and ${ }^{137} \mathrm{Cs}$ and then cast into canisters to form the final immobilized product.

4. Adjunct Melter-a two-step vitrification process similar to that for the Greenfield Vitrification case. The Pu-glass frit is prepared as above except that the initial vitrification is carried out in existing Pu-processing gloved-box facilities at Savannah River. This prepared Pu-glass frit is then transported to a new melter facility near the DWPF. There, it is remelted with additional borosilicate glass frit (also containing neutron absorbers) and ${ }^{137} \mathrm{Cs}$ from the HLW waste tanks $\left({ }^{137} \mathrm{Cs}\right.$ is separated from HLW supernate as a routine step in the DWPF operations at Savannah River). The molten glass, containing the plutonium and ${ }^{137} \mathrm{Cs}$, is cast into large DWPF canisters for subsequent disposal.

5. Greenfield Ceramic-a single-step process carried out in new facilities in which $\mathrm{Pu}$ and ${ }^{137} \mathrm{Cs}$ are combined with ceramic precursors and hot-pressed to form a mineral-like material contained in metal canisters. 
6. Electrometallurgical Treatment-a variation of the waste disposal process of the Integral Fast Reactor fuel cycle technology in which the plutonium is loaded onto a zeolite along with ${ }^{137} \mathrm{Cs}$. The zeolite is then hot-pressed with glass formers to produce the immobilized form.

The following assumptions were used to define the facility concepts for the immobilization variants (Ref. 3-9):

- The operational campaign for the immobilization facility will take no more than 10 years to complete.

- The nominal feed of plutonium to the facility is 50 tonnes. Nominal throughput is therefore $25 \mathrm{~kg}$ Pu per day for 200 days of operations per year for 10 years.

- The design for criticality safety will meet applicable DOE Orders and available Nuclear Regulatory Commission (NRC) regulator guides. Criticality is prevented by using batch mass control and/or equipment geometry as the preferred methods in the designs. The use of appropriate neutron absorbers (for example, gadolinium, samarium, hafnium) has been assumed.

- The immobilization canister shall not exceed $0.6 \mathrm{~m}$ in diameter by $3.0 \mathrm{~m}$ long.

- The immobilized plutonium package will contain an added radiation field to increase proliferation resistance. The gamma radiation field will be greater than $100 \mathrm{R} / \mathrm{hr}$ at $1.0 \mathrm{~m}$ from the package surface 30 years after initial fabrication.

\section{Evaluation Methodology}

Key attributes of the six immobilization technology variants were evaluated with respect to nine fissile materials disposition criteria and their corresponding metrics (described below and in Appendix A).

Each immobilization variant was defined for this analysis as the beginning-to-end set of operations (that is, from surplus plutonium to geologic disposal) necessary to address all of the surplus weapons-usable plutonium (that is, $\sim 50$ tonnes of pits and impure plutonium materials). The information assembled for each of the immobilization variants included:

- Block flow diagrams describing process steps for all operations.

- Lists of major equipment and facilities to accomplish each immobilization function.

- Mass balance and rate data for unit operations and facilities.

- Sketches of equipment layouts and plot plans.

- Reviews of regulatory and operational considerations for facilities.

- Estimates of facility sizes, personnel requirements, and facility infrastructure requirements.

- Identification of balance of plant requirements.

This information defined the immobilization variants in sufficient detail to permit technical assessments to be performed with respect to technical, cost, schedule, and 
other criteria. Limited experimental and development work was also performed to enhance the knowledge base, including:

- Laboratory-scale fabrication of glass and ceramic forms with plutonium.

- Full-scale "cold" (that is, without any radionuclides) demonstration of the can-incanister concept.

Data from the published reports of these studies will form the bases of the input data for this analysis (see Ref. 3-9).

\section{Evaluation Criteria}

The basic criteria used to evaluate the immobilization technology variants are those that have been used by the Fissile Materials Disposition Program in previous studies and decisions:

1. Resistance to Theft and Diversion by Unauthorized Parties. Each step in the disposition process must be capable of providing for comprehensive protection and control of weapons-usable fissile materials.

2. Resistance to Retrieval, Extraction, and Reuse by Host Nation. The surplus material must be made highly resistant to potential use in weapons to reduce reliance on institutional controls and demonstrate that the arms reduction will not be easily reversed.

3. Technical Viability. There should be a high degree of confidence that the alternative will be technically successful.

4. Environmental, Safety, and Health (ES\&H) Compliance. High standards of public and worker health and safety and environmental protection must be met, and significant additional ES\&H burdens should not be created.

5. Cost Effectiveness. Disposition should be accomplished in a cost-effective manner and be compatible with reasonable long-term storage alternatives.

6. Timeliness. There is an urgent need to begin Pu disposition and to minimize the time period the surplus fissile materials remain in weapons-usable form.

7. Fostering Progress and Cooperation with Russia and Other Countries. The alternatives must establish appropriate standards for disposition of surplus weapons-usable materials inventories and support negotiations for bilateral or multilateral reductions in these materials, and each step in the disposition process must allow for international inspections.

8. Public and Institutional Acceptance. An alternative should be able to muster a broad and sustainable consensus on the manner in which disposition is accomplished.

9. Additional Benefits. The ability to leverage government investments for disposition of surplus materials to contribute to other national or international initiatives should be considered.

Metrics for each criterion were developed by a committee composed of experts from the Immobilization Program representing LLNL, Argonne National Laboratory (ANL), 
Pacific Northwest National Laboratory (PNNL), SRS, and the Radioactive Waste Management (RW) contractor. The criteria and metrics are described in Appendix A.

\section{Comparison of Technology Variants}

\section{Overview}

A comparison of the technology options against the criteria are summarized in Table 2. Timeliness, technical viability, cost effectiveness, and nonproliferation (resistance to theft and diversion) are the major criteria discriminators for technology. The other criteria (fostering progress and cooperation, public and institutional acceptance, and additional benefits) did not discriminate among the options.

In general, the two can-in-canister (glass and ceramic) variants are clearly superior to the four homogeneous form variants in the areas of timeliness, technical viability, and cost, and they are slightly better with respect to ES\&H factors. The homogeneous forms offer somewhat better proliferation resistance, although the can-in-canister variants afford a sufficient degree of proliferation resistance to meet the intent of the spent fuel standard.

A brief discussion of the analysis follows for each of the discriminating criteria.

\section{Resistance to Theft and Diversion by Unauthorized Parties}

Discussion. The applicable metrics for evaluating the technology variants for resistance to theft and diversion by unauthorized parties are: number of facilities and processing complexity (risk of diversion or theft from processing facilities), and separability (degree of difficulty) of plutonium from the final form. The homogeneous form options for glass and ceramic score higher on number of facilities (one versus two facilities for can-in-canister) and on difficulty of separating the plutonium. The latter property results from the fact that, in the homogeneous forms, the plutonium and ${ }^{137} \mathrm{Cs}$ are intimately mixed in a single solid matrix. In the can-in-canister options, the plutonium and ${ }^{137} \mathrm{Cs}$ are physically separated. In both cases, ${ }^{137} \mathrm{Cs}$ is the isotope that provides the radiation barrier.

As pointed out by an independent nonproliferation review panel (Nonproliferation Team, Ref. 12), the small cans of plutonium forms could possibly be surgically removed from the waste package (and the radiation barrier) by an unauthorized party, for example, with the use of shaped explosives. There are, however, several mitigating measures that could be applied to reduce this already small risk, if deemed necessary.

Based upon known chemistry of silicate and titanate minerals, the ceramic forms, either homogeneous or can-in-canister, are believed to be more resistant to chemical extraction and separation of plutonium than their corresponding glass forms. However, specific tests have yet to be performed. 
UCRL-ID- 127320

\begin{tabular}{|c|c|c|c|c|c|c|}
\hline VARIANT & $\begin{array}{l}\text { Vitrification } \\
\text { (glass) } \\
\text { Can-in- } \\
\text { Canister }\end{array}$ & $\begin{array}{l}\text { Ceramics } \\
\text { Can-in- } \\
\text { Canister }\end{array}$ & $\begin{array}{c}\text { Vitrification } \\
\text { (glass) } \\
\text { Homogeneous } \\
\text { (Greenfield) }\end{array}$ & $\begin{array}{c}\text { Ceramics } \\
\text { Homogeneous } \\
\text { (Greenfield) }\end{array}$ & $\begin{array}{l}\text { Adjunct } \\
\text { Melter }\end{array}$ & $\begin{array}{c}\text { Electrometal- } \\
\text { lurgical } \\
\text { Treatment }\end{array}$ \\
\hline $\begin{array}{l}\text { METRIC } \\
\text { Theft \& Diversion } \\
\text { Number of Facilities } \\
\text { Separability from Radiation } \\
\text { Barrier }^{1}\end{array}$ & $\begin{array}{c}2 \\
\begin{array}{c}\text { Mechanical or } \\
\text { Chemical }\end{array} \\
\end{array}$ & $\begin{array}{c}2 \\
\text { Mechanical or } \\
\text { Chemical } \\
\end{array}$ & $\begin{array}{c}1 \\
\text { Chemical }\end{array}$ & $\begin{array}{c}1 \\
\text { Chemical }\end{array}$ & $\begin{array}{c}2 \\
\text { Chemical }\end{array}$ & $\begin{array}{c}4 \\
\text { Chemical }\end{array}$ \\
\hline $\begin{array}{l}\text { Host Nation Extraction } \\
\text { Cost to Modify Purex Head-end } \\
\text { to Facilitate Processing }\end{array}$ & $\begin{array}{c}\text { Minor } \\
\text { modification }\end{array}$ & $\begin{array}{c}\text { Major } \\
\text { modification }\end{array}$ & $\begin{array}{c}\text { Minor } \\
\text { modification }\end{array}$ & $\begin{array}{c}\text { Major } \\
\text { modification }\end{array}$ & $\begin{array}{c}\text { Minor } \\
\text { modification }\end{array}$ & $\mathrm{TBD}^{2}$ \\
\hline $\begin{array}{l}\text { Technical Viability } \\
\text { Stage Of Development } \\
\text { Viability Risks } \\
\text { Confidence of Acceptability } \\
\end{array}$ & $\begin{array}{c}2 \\
\text { Low } \\
\text { High } \\
\end{array}$ & $\begin{array}{c}2 \\
\text { Low } \\
\text { High } \\
\end{array}$ & $\begin{array}{c}1 \\
\text { High } \\
\text { High } \\
\end{array}$ & $\begin{array}{c}2 \\
\text { Moderate } \\
\text { High } \\
\end{array}$ & $\begin{array}{c}1 \\
\text { High } \\
\text { High } \\
\end{array}$ & $\begin{array}{c}1 \\
\text { High } \\
\text { Low } \\
\end{array}$ \\
\hline $\begin{array}{l}\text { ES\&H } \\
\text { New Construction } \\
\text { Known and Manageable Waste } \\
\text { Forms }\end{array}$ & $\begin{array}{l}\text { Minimal } \\
\text { Yes }\end{array}$ & $\begin{array}{l}\text { Minimal } \\
\text { Yes }\end{array}$ & $\begin{array}{l}\text { Major } \\
\text { Yes }\end{array}$ & $\begin{array}{c}\text { Major } \\
\text { Yes }\end{array}$ & $\begin{array}{c}\text { Minimal } \\
\text { Yes }\end{array}$ & $\begin{array}{c}\text { Minimal } \\
\text { Questionable }\end{array}$ \\
\hline $\begin{array}{l}\text { Cost Effectiveness } \\
\text { Net Life Cycle Cost, \$ Millions } \\
\text { Start-up Costs, \$ Millions } \\
\text { Utilization of Existing } \\
\text { Infrastructure }\end{array}$ & $\begin{array}{l}1810 \\
560 \\
\text { Yes }\end{array}$ & $\begin{array}{l}1810 \\
560 \\
\text { Yes }\end{array}$ & $\begin{array}{c}4670 \\
1810 \\
\text { No all new }\end{array}$ & $\begin{array}{c}4670 \\
1810 \\
\text { No all new }\end{array}$ & $\begin{array}{c}3630 \\
1020 \\
\text { Yes plus new }\end{array}$ & $\begin{array}{c}3430 \\
1190 \\
\text { Yes plus new }\end{array}$ \\
\hline $\begin{array}{l}\text { Timeliness } \\
\text { Years to Start } \\
\text { Years to Complete } \\
\text { Impact on Existing Site } \\
\text { Missions } \\
\end{array}$ & $\begin{array}{c}7 \text { to } 11^{3} \\
17 \text { to } 21^{3} \\
\text { Moderate }\end{array}$ & $\begin{array}{c}7 \text { to } 11^{3} \\
17 \text { to } 21^{3} \\
\text { Moderate }\end{array}$ & $\begin{array}{c}12 \\
22 \\
\text { Moderate to }^{\text {Large }^{3}} \\
\end{array}$ & $\begin{array}{c}12 \\
22 \\
\begin{array}{c}\text { Moderate to } \\
\text { Large }^{3}\end{array}\end{array}$ & $\begin{array}{c}12 \\
22 \\
\text { Moderate }\end{array}$ & $\begin{array}{c}13 \\
23 \\
\text { Large }\end{array}$ \\
\hline
\end{tabular}

1 Requires shielded facilities

2 Experiments have not yet been done to allow determination of this metric.

3 Site dependent. 
This was also pointed out in the independent nonproliferation review of the disposition alternatives (Ref. 12).

Processing complexity (number of processing steps), as it applies to proliferation resistance, does not appear to be a significant discriminator among the three glass technology variants or among the two ceramic variants. Experiments underway will give an indication of how significant a discriminator processing complexity will be between glass and ceramics.

Conclusion. The homogeneous forms offer somewhat better resistance to theft and diversion than the can-in-canister forms. However, the difference is small between the homogeneous and nonhomogeneous variants because the can-in-canister forms can readily be designed to mitigate against this type of proliferation.

\section{Resistance to Retrieval, Extraction, and Reuse by Host Nation}

Discussion. The key metric in the resistance to host nation retrieval, extraction, and reuse is the cost and time to modify existing facilities (or perhaps construct new facilities) and perform the operations needed to separate 1.0 tonne of pure plutonium from the immobilized form. Large shielded facilities exist in Russia and the U.S. associated with reactor fuel and target reprocessing. The major distinction between the immobilization forms with respect to this criterion is whether these existing facilities can be used as is or with modifications, or whether new facilities would have to be built. It appears that, with fairly modest and relatively cheap modification, the existing "canyon" facilities could be used to extract large amounts of plutonium from the glass forms. This is due to the fact that plutonium can be readily leached from the glass forms into nitric acid after the glass has been crushed. On the other hand, based upon limited testing, nitric acid will not leach appreciable quantities of plutonium from the ceramic forms. Based upon data from the mining industry, ceramics will have to be finely ground and then taken through a double decomposition-type reaction to convert the titanate matrix into a soluble form. Processing the ceramics would require either very extensive, costly, and time-consuming modifications to the head-end of both the U.S. and Russian plutonium processing facilities or the construction of new facilities.

Conclusion. The homogeneous glass and ceramic forms are somewhat more resistant to plutonium extraction by the host nation than their can-in-canister counterparts. Based upon limited data, the ceramic forms apparently are somewhat more resistant to plutonium extraction than the glass forms. For any of these forms, reuse of plutonium by the host nation would be costly and time consuming.

\section{Technical Viability}

Discussion. The three principal metrics used to assess the technical viability of the immobilization technology variants are: 
1. Technical maturity or readiness to deploy the technology (see scale in Appendix A).

2. Viability risk or likelihood of deploying the technology without major changes affecting cost and time.

3. Acceptability of the waste form by the repository.

The can-in-canister forms (both glass and ceramic) are by far the most technically mature (between 2 and 3 on the maturity scale versus 1 to 2 for the homogeneous forms). The can-in-canister processes have been developed and evaluated sufficiently. so that they pose a significantly lower viability risk than any of the homogeneous forms. Furthermore, the homogeneous forms involve processes that are generally more complex and require a greater number of operations in hot-cell or canyon-type facilities. In addition, developing formulations for the homogeneous glass and ceramic forms is much more difficult due to the coprocessing of ${ }^{137} \mathrm{Cs}$ (which has relatively high volatility) with plutonium in a high-temperature formation process.

Regarding repository qualification, existing, but incomplete, information on the glass and ceramic can-in-canister forms gives reasonable assurance that these waste forms can be qualified for disposal in the HLW repository. Although the formulation development for the homogeneous glass and ceramic forms has not progressed as far as for the can-in-canister forms, there is reasonable confidence that these forms could also be qualified. The glass-bonded zeolite, on the other hand, is much more problematic because of the lower chemical durability of the material under expected repository conditions.

Conclusion. The technical viability of both can-in-canister technologies is significantly higher for the homogeneous immobilization technologies.

\section{Environmental, Safety, and Health Compliance}

Discussion. As shown in the PEIS (Ref. 1), ES\&H factors are not major discriminators between ceramic and glass immobilization because all of the facilities will be designed to meet applicable standards and requirements for safety and environmental emissions. However, design and construction requirements dictated by ES\&H factors would be reflected in the costs and possibly the implementation times of the variants. There is one notable distinction that can be made between the homogenous and can-in-canister variants. The homogeneous variant requires much more heavily shielded facilities, including new Class I buildings, which would translate into higher ES\&H risks.

Conclusion. There are only minor distinctions among the immobilization technologies with respect to ES\&H factors. The major difference is the additional ES\&H risks associated with the more extensive shielding facilities associated with the homogeneous options. 


\section{Cost Effectiveness}

Costs of the facility concepts for each of the technology variants were estimated during the ROD process at the $\pm 50 \%$ level. Cost estimates are listed in Table 3 . The canin-canister options are clearly less expensive than the homogeneous technology options (by at least a factor of 2). This is a direct result of their greater utilization of existing plutonium processing facilities and the use of either the DWPF at Savannah River or the new vitrification facility at Hanford.

Table 3. Immobilization Alternative Costs.

Constant \$ (millions)

\begin{tabular}{|c|c|c|c|c|}
\hline Immobilization Alternative & Facility & Investment & Operating & $\begin{array}{c}\text { Net Life Cycle } \\
\text { Cost }\end{array}$ \\
\hline \multirow[t]{4}{*}{ Vitrification, Greenfield } & Front-end & 1000 & 980 & 1980 \\
\hline & Immobilization & 1030 & 1800 & 2830 \\
\hline & Repository & 0 & 300 & 300 \\
\hline & Total & 2030 & 3080 & $\mathbf{5 1 1 0}$ \\
\hline \multirow[t]{4}{*}{ Vitrification, Can-in-Canister } & Front-end & 340 & 980 & 1320 \\
\hline & Immobilization & 220 & 170 & 390 \\
\hline & Repository & 0 & 100 & 100 \\
\hline & Total & 560 & 1250 & 1810 \\
\hline \multirow[t]{4}{*}{ Vitrification, Adjunct Melter } & Front-end & 340 & 980 & 1320 \\
\hline & Immobilization & 680 & 1330 & 2010 \\
\hline & Repository & 0 & 300 & 300 \\
\hline & Total & 1020 & 2610 & 3630 \\
\hline \multirow[t]{4}{*}{ Ceramic, Greenfield } & Front-end & 860 & 820 & 1680 \\
\hline & Immobilization & 950 & 1720 & 2670 \\
\hline & Repository & .0 & 320 & 320 \\
\hline & Total & 1810 & 2860 & 4670 \\
\hline \multirow[t]{4}{*}{ Ceramic, Can-in-Canister } & Frontend & 340 & 980 & 1320 \\
\hline & Immobilization & 220 & 170 & 390 \\
\hline & Repository & 0 & 100 & 100 \\
\hline & Total & 560 & 1250 & 1810 \\
\hline Electrometallurgical & Front-end & 730 & 890 & 1620 \\
\hline \multirow[t]{3}{*}{ Treatment } & Immobilization & 460 & 870 & 1330 \\
\hline & Repository & 0 & 480 & 480 \\
\hline & Total & 1190 & 2240 & $3430^{1}$ \\
\hline
\end{tabular}

Costs are based upon a stand-alone plutonium disposition mission. Cost sharing with DOE programs for the treatment of spent fuel has the potential to reduce costs by approximately $\$ 600$ million. 


\section{Timeliness}

Timeliness is a critical criterion. This was indicated by the U.S. National Academy of Sciences report on fissile materials disposition (Ref. 11) and in recommendations of the Nonproliferation Task Force report (9/96) to the Secretary of Energy's Advisory Board on Nonproliferation (Ref. 12). Both of these review panels deemed the excess fissile materials to be a "clear and present danger" and emphasized that timeliness should have priority over cost. To be responsive to this view, the DOE plans to have an immobilization facility ready to operate as soon as possible, but within 10 years of the PEIS ROD.

Of the immobilization alternatives, the can-in-canister (glass and ceramic) variants have the shortest deployment time and the highest assurance that deployment can be achieved within 10 years. The primary reasons for this are their use of existing plutonium processing facilities for the first stage of immobilization and the use of the existing DWPF at Savannah River to add the radiation barrier.

\section{Conclusion}

The can-in-canister technology variants, based on our current state of knowledge, are clearly superior to the homogeneous immobilization options in the areas of timeliness, technical viability, and cost effectiveness, and they are slightly better with respect to ES\&H factors. Although somewhat less proliferation resistant than the homogeneous forms, the can-in-canister technology can be designed and deployed in a manner that meets the "Spent Fuel Standard." 


\section{References}

1. Storage and Disposition of Weapons-Usable Fissile Materials Final Programmatic Environmental Impact Statement, U.S. Department of Energy, Washington, DC, December, 1996.

2. Record of Decision for the Storage and Disposition of Weapons-Usable Fissile Materials Final Programmatic Environmental Impact Statement, U.S. Department of Energy, January 14, 1997.

3. Alternative Team Technical Data Document: Vitrification Can-in-Canister Alternative, L-20215-1, UCRL-122663, August 26, 1996.

4. Alternative Team Technical Data Document: Vitrification Can-in-Canister Alternative, L-20216-1, UCRL-122659, August 26, 1996.

5. Alternative Team Technical Data Document: Vitrification Adjunct Melter to DWPF Alternative, L-20217-1, UCRL-122660, August 26, 1996.

6. Alternative Team Technical Data Document: Ceramic Greenfield Alternative, L-20218-1, UCRL-122662, August 26, 1996.

7. Alternative Team Technical Data Document: Ceramic Can-in-Canister Alternative, L-20219-1, UCRL-122661, August 26, 1996.

8. Alternative Team Technical Data Document: Electrometallurgical Treatment Alternative, L-20220-1, UCRL-122664, August 26, 1996.

9. Technical Summary Report for Surplus Weapons-Usable Plutonium Disposition, Office of Fissile Materials Disposition, U.S. Department of Energy, DOE/MD-0003, July 17, 1996, Rev. 0.

10. Gould, T., "Plutonium Immobilization Decision Process," Lawrence Livermore National Laboratory, Livermore, CA, FM97001, January 14, 1997.

11. John P. Holdren, et al., Management and Disposition of Excess Weapons Plutonium, National Academy of Sciences, National Academy Press, Washington D.C. 1994

12. Nonproliferation and Arms Control Assessment of Weapons-Usable Fissile Material Storage and Plutonium Disposition Alternatives-Department of Energy Office of Arms Control and Nonproliferation, DOE/NN-0007, January 1997. 
UCRL-ID-127320

\section{APPENDIX A}

\section{Criteria and Metrics Descriptions for Immobilization Selection Process}

\section{Introduction}

The criteria to be used to evaluate the immobilization technology variants are those that have been used by the Fissile Materials Disposition Program in studies and decisions (Ref. 1):

1. Resistance to Theft and Diversion by Unauthorized Parties. Each step in the disposition process must be capable of providing for comprehensive protection and control of weapons-usable fissile materials.

2. Resistance to Retrieval, Extraction, and Reuse by Host Nation. The surplus material must be made highly resistant to potential use in weapons to reduce reliance on institutional controls and demonstrate that the arms reduction will not be easily reversed.

3. Technical Viability. There should be a high degree of confidence that the alternative will be technically successful.

4. Environmental, Safety, and Health Compliance. High standards of public and worker health and safety and environmental protection must be met, and significant additional ES\&H burdens should not be created.

5. Cost Effectiveness. Disposition should be accomplished in a cost-effective manner and be compatible with reasonable long-term storage alternatives.

6. Timeliness. There is an urgent need to begin Pu disposition and to minimize the time period the surplus fissile materials remain in weapons-usable form.

7. Fostering Progress and Cooperation with Russia and Other Countries. The alternatives must establish appropriate standards for disposition of surplus weapons-usable materials inventories and support negotiations for bilateral or multilateral reductions in these materials, and each step in the disposition process must allow for international inspections.

8. Public and Institutional Acceptance. An alternative should be able to muster a broad and sustainable consensus on the manner in which disposition is accomplished.

9. Additional Benefits. The ability to leverage government investments for disposition of surplus materials to contribute to other national or international initiatives should be considered.

Metrics for each criteria were developed by a committee composed of experts from the Immobilization Program representing LLNL, ANL, PNNL, SRS, and the RW contractor. Criteria and metrics are described below. This criteria set was developed to support both the technology and site selection processes. 


\section{Discussion of Metrics}

\section{Criterion 1. Resistance to Theft or Diversion by Unauthorized Parties}

This first criterion addresses the risk of theft of weapon-usable nuclear material by terrorists, subnational groups, or aspiring nuclear states, in addition to potential theft by disgruntled employees. This threat exists throughout all phases of disposition: transportation, storage, processing, as well as after immobilization has been completed.

In general, risk can be reduced by rapidly achieving a low-material attractiveness (material characteristics), minimizing the handling, processing, and transportation of the material (environment), and applying effective safeguards and security (S\&S) measures. ["International Atomic Energy Agency (IAEA) safeguards should be applied to excess fissile material... as early as ...possible. As disposition is intended to reduce the risk of proliferation rather than increasing it, it is critical to maintain stringent standards of safeguards and security throughout the process. Physical security approaches to be applied to all phases of the disposition processes should be developed jointly with Russia, the IAEA, and, where relevant, with other nations involved in the process." Secretary of Energy Advisory Board Task Force, September 26, 1996.]

The transportation, storage, and processing must, where meaningful, meet the Stored Weapons Standard, and the condition after disposition must be roughly equal to the proliferation resistance of commercial spent fuel (i.e., the Spent Fuel Standard ${ }^{2}$ ).

Note: While repository acceptability is considered under Criterion 3, the final disposition site (repository) is not being considered as a discriminator in this evaluation. All immobilized forms are assumed to go to the same final disposition location.

Note: Timeliness of start-up and mission completion are covered under Criterion 6.

Factors to be considered when applying this criterion are:

A. Low Inherent Attractiveness: This factor favors immobilization options that rapidly lower the attractiveness of the physical, chemical, or isotopic makeup of the nuclear material.

1 The Stored Weapons Standard was defined by the National Academy of Sciences to mean that, to the extent possible, the high standards of security and accounting applied to the storage of intact nuclear weapons should be maintained for these materials throughout dismantlement, storage, and disposition.

2 The Spent Fuel Standard was defined by the National Academy of Sciences to mean that options for the disposition of plutonium should seek to make this plutonium roughly as inaccessible or unattractive for weapons use as the much larger and growing stock of plutonium in civilian spent fuel. 


\section{Metrics:}

1. DOE Attractiveness (Applies to process and form) Processing time to reach Category and Attractiveness Level II-D or lower, as defined by DOE Order 5633.3B

2. Other Fissile Material (Applies to site and process) Minimization of processing/separation/handling of fissile material other than $\mathrm{Pu}$. The presence of other separated fissile material in a process or facility represents a possible diversion path.

B. Minimization of Transportation, Facilities, and Sites: The more complex the logistics, the more opportunities there are for theft. Immobilization scenarios that involve complex logistics with many transfers and storage locations, with attendant transportation requirements, are considered to be more vulnerable to theft.

\section{Metrics for Environment:}

1. Number of Safe, Secure, Transport (SST) Miles (Applies to site) Total number of miles traveled, requiring an SST, to take $\mathrm{Pu}$ through the alternative (end-to-end).

2. Number of Trips (Applies to site)

Total number of trips traveled, requiring an SST, to take Pu through the alternative (end-to-end).

3. Number of Facilities (Applies to site)

Total number of facilities that the $\mathrm{Pu}$ resides within end-to-end.

C Minimization of Processing: The more complex processing, the more opportunities there are for theft. Immobilization scenarios that involve many complex processing steps and bulk (not item) materials, are considered to be more vulnerable to theft.

\section{Metrics:}

1. Number of Processing Steps (Applies to site and process) The number of times that Pu changes physical or chemical form. (Does not include shipping/receiving, etc.)

2. Complexity of Processing (Applies to process and form) Measure of the processing complexity. 
D. Safeguards and Security Assurance: The effectiveness of the S\&S protection depends on the form of the fissile material and the characteristics of the processes and facilities involved in the immobilization activities.

Metrics:

1. Measurement Uncertainty (Applies to process and form)

The confidence level associated with the ability to measure the amount of Pu existing in a form. Task is made more difficult by other radioactivity, attenuators, etc. Factor is expressed as a percentage and is based on future technology capabilities (best guess if technology is researched and developed).

2. Accessibility (Applies to site, process, and form)

Accessibility is a combination of three separate factors. Each has two possible conditions. The first is the accessibility of the plutonium itself. Is the $\mathrm{Pu}$ material able to be touched (T) or is it in a sealed container (C)? Second is the accessibility of the container or material. Is it hands-on (H) or requiring remote handling (R)? Third is whether the target is in a large and/or bulky form that requires special handling equipment to be moved $($ Yes $=\mathbf{Y})$ or not $(\mathrm{No}=\mathbf{N})$.

E Difficulty of Retrieval, Extraction, and Use by a Clandestine Group or Rogue Nation: This factor considers the difficulty of retrieval of surplus weaponsusable material and its possible use in clandestine weapons.

Reprocessing: Refers to cost and time to reprocess one significant quantity (SQ) given one target in possession (based on easily developed experimental data).

\section{Metrics:}

1. Location (Applies to site, process, and form) Time $\mathrm{Pu}$ spends under inherently less secure conditions (i.e., processing vs. storage) and the S\&S barriers in effect.

2. Time and Cost to Reprocess (Applies to form) Measure of time to process one significant quantity (SQ).

3. Detectability of Reprocessing Activities (Applies to form) Measure of detectable "signatures" produced to reprocess one significant quantity (SQ).

4. Separability from Radiation Barrier (Applies to form) Measure of relative ease to remove Pu-bearing matrix from high-level radiation barrier matrix. 
UCRL-ID-127320

\section{Criterion 2. Resistance to Retrieval, Extraction, and Reuse by the Host Nation}

The goal is to make it unlikely that surplus weapons-usable materials will ever be used in weapons. ["Ensuring irreversibility, and in particular ensuring that the plutonium in the forms and locations resulting from disposition would be roughly as inaccessible and unattractive for use in weapons by the host state as plutonium in commercial spent fuel, is also critical to achieving the objectives of disposition. Achieving this 'Spent Fuel Standard' will contribute to encouraging Russia to take comparable steps in parallel, to reducing the risk of reversal of ongoing arms reductions and laying the basis for further reductions, and to politically strengthening the nonproliferation regime by demonstrating the $U$. S. commitment that its reductions will not be reversed." Secretary of Energy Advisory Board Task Force, September 26, 1996] High resistance to retrieval would provide confidence to other nations that a relatively large resource expenditure (cost and time) would be required to reconstruct the stockpile from disposed material. Barriers to reuse include the form of the material, physical location of the material, and institutional controls (such as IAEA Safeguards). A goal of disposition is to reduce reliance on institutional controls.

Modification of weapons-usable material to make it "roughly" as difficult to use for weapons production as Pu contained in spent commercial reactor fuel would make the rearmament threat associated with surplus weapons-usable materials no greater than the threat resulting from $\mathrm{Pu}$ in spent fuel, and materials would no longer require a unique level of domestic and international safeguards.

For specific issues to be addressed in current immobilization evaluations, the "Host Nation" is the United States. However, the motivation for taking material disposition actions are additionally driven by concerns in Russia, as well as other nations. How our actions would foster progress and cooperation with Russia to provide effective disposition of their materials is addressed in Criterion 7, discussed below.

Note: The final disposition site (repository) is not being considered as a discriminator in this evaluation. All immobilized forms are assumed to go to the same disposition location.

Note: Timeliness of start-up and mission completion are covered under Criterion 6.

Factors considered when applying this criterion are:

A. Difficulty of Retrieval, Extraction, and Reuse: This factor considers the difficulty of retrieval of surplus weapons-usable material and its reuse in weapons. For this criterion, breakout is assumed to be the recovery of one tonne of plutonium by the Host Nation. Since both the U.S. and Russia have plutonium processing and purification plants that use the PUREX process, breakout is assumed to be carried out by the appropriate 
modifications to these plutonium processing plants. These plants include both 221-F and 221-H Separations Canyons at Savannah River in the U.S., the Siberian Chemical Combine at Tomsk-7 (Seversk), and the Mayak Production Association at Chelyabinsk in Russia.

\section{Metrics:}

1. Time and Cost to Retrieve/Reprocess (Applies to form) Measure of time and cost for Host Nation to reprocess one tonne.

2. Health Risk to Retrieve/Reprocess (Applies to form) Measure of health risk for Host Nation to reprocess one tonne.

3. Separability from Radiation Barrier (Applies to form) Measure of relative ease for Host Nation to remove Pu-bearing matrix from high-level radiation barrier matrix.

B. Assurance of Detection of Diversion and Extraction: This factor primarily deals with how difficult the material would be to retrieve and extract in a clandestine manner, which depends on the resultant material location and form.

\section{Metrics:}

1. Measurement Uncertainty (Applies to process and form) The confidence level associated with the ability to measure the amount of $\mathrm{Pu}$ existing in a form. Task is made more difficult by other radioactivity, attenuators, etc. Factor is expressed as a percentage and is based on future technology capabilities (best guess if technology is researched and developed).

2. Accessibility (Applies to site and form)

Accessibility is a combination of three separate factors. Each of the three factors has two possible conditions. The first is the accessibility of the plutonium itself. Is the $\mathrm{Pu}$ material able to be touched $(\mathrm{T})$ or is it in a sealed container (C)? Second is the accessibility of the container or material. Is it hands-on (H) or requiring remote handling $(\mathbf{R})$ ? Third is whether the target is in a large and/or bulky form that requires special handling equipment to be moved $($ Yes $=Y)$ or $\operatorname{not}(\mathrm{No}=\mathbf{N})$.

3. Delectability of Reprocessing Activities (Applies to form) Measure of detectable "signatures" produced for Host Nation to reprocess one tonne. 


\section{Criterion 3. Technical Viability}

There should be a high degree of confidence that an alternative will be technically successful. It is therefore of interest to rely on technologies that have been proven for similar applications and have a high likelihood of success. New technologies (or new applications of old technologies) may also require an extended period for licensing or regulatory approval due to the immaturity of the process or regulatory framework. This includes the state, readiness, and projected lifetime of facilities and infrastructure and the processing/storage/disposal capacity of the facilities. Technical viability can be applied to complete global processes or to unit operations within the overall process.

Factors to be considered when applying this criterion are:

A. Technical Maturity: Near-term actions require mature and proven processes. Technologies that are less mature may require a number of years to prove themselves and increase the risk that they will not meet technical goals, be adequately mature for deployment, or be more costly and take more time than projected.

\section{Metrics:}

Readiness of the Process for Deployment (Applies to process and form) The metric for technical maturity is readiness for deployment. Readiness for deployment is based on the stage of development, as measured using the seven stages listed in Table A-1. [This is an adaptation of the gate process used by both the Department of Defense and the DOE Environmental Remediation and Waste Management (EM) Office of Science and Technology.] The current stage of development is based on whether all of the criteria for completion of the previous stage have been met.

\section{B. Viability Risks: (Applies to process)}

There is a risk to the program associated with getting the process from where the experts think we are today in a given option (unit operation by unit operation) to Stage 7 . The viability risk will be based upon expert judgment utilizing comparisons with like-unit operations, where available, in use in various industries today. The seven stages in Table A-1 will be utilized to determine these risks.

C Repository Acceptability of Disposal Form: The immobilization form must be acceptable for disposal in the federal repository. Acceptability of the disposal form for disposal in a geologic repository is a fitness-for-purpose criterion that has regulatory and licensing implications as well as long-term post-emplacement performance implications from non-proliferation and ES\&H perspectives. There are a number of regulatory requirements that 
UCRL-ID-127320

Table A-1. Technical Maturity.

Stage of

development

Criteria for completion

1 Basic research Benchtop cold experiments are successful.

2 Applied research

Benchtop experiments with radioactive material are successful. All of the process steps have been successfully demonstrated with expected average feedstock (success means that the desired product has been produced-in terms of product quality-with the required loading of $\mathrm{Pu}$; or that the output of the process step, for example, pretreatment, has achieved its desired goals).

3 Exploratory development

Performance and costs of process and product are reasonably established. Product requirements are clearly defined. Integrated demonstrations on a laboratory scale with the full range of radioactive feedstocks (of the appropriate chemical and physical forms) expected to be processed have been successfully completed.

4 Advanced development

All showstoppers have been eliminated. Costs are favorable. The program is ready to proceed to develop functional design requirements for the process or form. At the completion of this stage, there should be confidence that the process can be operated reliably in a glovebox or remote environment.

$5 \quad$ Engineering development

Functional design requirements have been developed. Site readiness issues are identified, and addressed (thus, one cannot exit this stage until a site is selected). This includes provision for disposition of off-specification products and for treatment of secondary wastes.

6 Demonstration

The process and form are successfully demonstrated on a large enough scale so that implementation is straightforward (i.e., there are no scale-up issues). This can be achieved either radioactively or nonradioactively, with the radioactive option normally being preferred. The quality control/quality verification program for the product is validated. No technical issues remain that will impart risk to implementation (e.g., testing has been sufficiently rigorous so that there is confidence that the process or form will tolerate credible upset conditions).

7 Implementation

must be satisfied by the disposal form. These requirements are listed in Table A-1. With the exception of requirement 1.4, which is covered more extensively below, these pass-fail requirements are the same for all variants, and hence not discriminators. The issue of post disposal proliferation resistance is dealt with separately in criteria 1 and 2, and predisposal ES\&H issues are dealt with separately in criterion 4 . Therefore, only the regulatory and licensing requirements and postemplacement ES\&H performance issues affecting acceptability for repository disposal are considered here. 
The two main long-term postemplacement performance considerations affecting repository acceptability are criticality safety and the potential for contamination of the biosphere by the release and transport of radioactive materials to the accessible environment. There may be substantial differences between long-term postemplacement ES\&H performance of different disposal forms. These differences could provide a basis for differentiating between disposal forms.

- Postemplacement Criticality Safety:

The disposal form emplaced in the geologic repository must remain criticality safe over the performance period. In the U.S., the current regulatory performance period for HLW and spent fuel in a geologic repository has been specified as 10,000 years. (The pertinent regulations are currently under review, and this may change.)

However, the emplaced plutonium and its ${ }^{235} \mathrm{U}$ decay product remain fissile over much longer periods ( $\mathrm{Pu}$-hundreds of thousands of years, 235 U-billions of years) over which criticality safety may need to be assured.

Scenarios for criticality events can be divided into three categories: criticality. safety of the "essentially undisturbed" waste package, criticality safety of degraded configurations of disrupted waste packages, and criticality safety of fissile materials that have been transported out of a failed waste package. Criticality safety of the first category of scenarios can be assured with very high confidence, but assuring the safety of the last two categories is more difficult and will depend on many factors.

Notwithstanding the complexity of the problem, key properties of disposal forms that affect criticality safety can be identified for the purpose of selecting a preferred disposal form. The key properties are the concentration of neutron absorbers, neutron absorption properties of the immobilization matrix, the resistance to release and transport by groundwater of disposal form constituents, and the rates and relative timing of releases of different components. The release characteristics may be very different for different disposal and are affected by the compositions of the groundwater and disposal form, the solubility of the constituents, active surface areas available for reaction with water, compositional and thermal stability of disposal forms, physical and chemical homogeneity of disposal forms, and radiation effects.

Postemplacement Isolation of Contaminants from Biosphere:

The disposal form emplaced in the geologic repository must remain isolated from the biosphere over the performance period. The performance period for isolation of the radionuclides present in HLW and spent fuel for a 
geologic repository in the U.S. has been specified as 10,000 years. (The pertinent regulations are currently under review, and this may change.)

Key disposal form properties that affect contaminant migration can be identified for the purpose of selecting a preferred disposal form without detailed consideration of the complex problem of possible contamination of the biosphere. These factors are essentially the same as those considered previously for criticality safety.

\section{Metrics:}

1. Criticality Safety and Contaminant Isolation from Biosphere for Site: Not a processing site discriminator.

2. Criticality Safety and Contaminant Isolation from Biosphere for Process and Form: (Applies to form)

Computed as a weighted average of the metrics for neutron absorption, leach resistance, colloid generation resistance, and mechanical stability.

3. Neutron Absorption:

Fabricated effective thermal neutron absorption cross-section (for all constituents in disposal form).

4. Leach Resistance:

Computed as a weighted average of the metrics for reciprocal dissolution rate, reciprocal active specific surface area, reciprocal radiation damage, reciprocal radiolysis effects, and colloid generation resistance.

5. Dissolution Rate:

Matrix dissolution rate from standard flow through test under specified standard conditions.

6. Active Specific Surface Area:

Estimated accessible surface area per unit volume at the time of emplacement in the repository.

7. Radiation Damage:

Increase in the release rate of matrix components due to radiation damage under agreed upon standard conditions

8. Variability of Dissolution Rate under Varying Chemical Conditions (includes radiolysis effects):

Equal to: $\left[\log \left(N R_{\mathrm{pH}-2}\right)-\log \left(N R_{\min }\right)+\log \left(N R_{\mathrm{pH}+2}\right)-\log \left(N R_{\min }\right)\right] / 4$, where $N R_{\min }$ is the normalized release rate of a matrix element at the $\mathrm{pH}$ of the minimum rate, and $N R_{-2}, N R_{+2}$ are the normalized release rates of that element measured at $2 \mathrm{pH}$ units below and above the $\mathrm{pH}$ of 
the minimum rate, respectively. All rates to be measured using saturated flow through tests under agreed upon test conditions.

9. Colloid Generation Resistance: (Applies to form)

The maximum fissile material mass concentration in a stable suspended colloid for a realistic, agreed upon fluid chemistry.

\section{Criterion 4. Environmental, Safety, and Health Compliance}

The goal is to select immobilization options that would provide safe and healthy conditions for workers and the public and provide as little environmental impact as possible.

Factors to be considered when applying this criterion are:

A. Public and Worker Health and Safety: This factor considers the risk of public and worker exposure to radiation and hazardous materials during transportation, storage, processing, and final disposition of the immobilized forms. As published in the PEIS, high standards of public and worker health and safety and environmental protection must be met, and significant additional ES\&H burdens should not be created. Exposure to workers and the public under normal operating conditions and in the event of an accident are considered.

Metrics for Site: $\quad$ Transportation miles (Applies to site)

Metrics for Process: Industrial hazards (Applies to process and form) Radiation exposure (Applies to process and form)

Contamination potential (Applies to site, process, and form)

B. Waste Minimization: This factor considers the potential impact of waste created by disposition options including transportation, storage, processing, and final disposition. It assessed the long-term, irreversible consequences of the disposition that are not captured by cost.

Metrics: Waste Disposition Pathway Identified (go/no go) (Applies to process)

C Known and Manageable Waste Forms: This factor considers the ability to deal with waste created by the disposition option. It would screen out options that create waste for which there is no known or likely practical treatment or disposal capability because the technical viability or costs of dealing with these wastes cannot be readily estimated.

Metrics: (go/no go) (Applies to process) 


\section{Criterion 5. Cost Effectiveness}

The goal is to minimize the incremental cost impact on the government and taxpayers. Timing, allocation, and uncertainties of costs were assessed. The following cost-related performance factors will be evaluated to determine the extent to which a particular option is cost-effective.

Factors to be considered when applying this criterion are:

A. Life Cycle Cost: Life cycle costs are defined as including: (1) development costs required to bring a technology to a state suitable for deployment; (2) deployment costs required to design, construct, and install the technology, including facility upgrades and refurbishments; (3) operating costs, including operators, supervisors, consumable materials, replacement melters or furnaces, and waste handling and disposal, and (4) decommissioning and decontamination costs to remove the systems and dispose of solid wastes including gloveboxes, secondary containment, and ventilation systems.

\section{Metrics: Dollars (Applies to site, process, and form)}

There is also a subset of the life cycle cost metric that must be considered. Although these are captured in total life cycle cost, metrics listed in this subset affect the timing of the dollars spent. These are listed below.

B. Investment and Start-up Cost: Investment and start-up cost refers to research and development, including cost of establishing product acceptability, construction, retrofit, and program infrastructure costs that are incurred early in the program.

\section{Metrics: Dollars (Applies to site, process, and form)}

C. Establish Product Acceptability Requirements: This factor will assess the ability of each waste form to be accepted by the geologic repository. An estimation is required of cost and schedule to provide data and documentation to meet repository requirements. Differences between currently approved waste forms and the plutonium waste form options will be determined, and an estimation of impacts to cost, schedule, and technical aspects is needed. Ease of verification of product conformance to disposal specifications must also be considered; e.g., can representative samples be extracted from the process or must the final product be characterized to meet the characterization acceptance requirement?

\section{Metrics: Dollars and Time (Applies to form)}

D. Potential for Cost Sharing: Potential cost sharing refers to other government agencies or private industry partial funding of the immobilization effort. Some immobilization options may provide benefits to these organizations 
such as demonstration of a new technology or production of a useful product.

Metrics: Dollars. However, the only program identified was the 94-1 plutonium stabilization program. Both glass and ceramics were judged to have about the same potential. Therefore, this is a low or nondiscriminator. (Applies to process and form)

E. Utilization of Existing Infrastructure: Utilization of existing infrastructure refers to the use of existing facilities with associated infrastructure (e.g., safeguards and security and analytical support for plutonium disposition). This use might affect the cost, environmental, or socioeconomic impacts of plutonium disposition.

\section{Metrics: Dollars (Applies to site)}

F. Cost Estimate Certainty: Cost estimate certainty refers to the level of confidence regarding forecast costs of an option and actual cost that would be incurred if the option is selected. Cost estimates must be based upon assumptions and approximations and may be in error. Cost estimate certainty was lower for those technology options that are in the research and development stage and higher for mature technologies or existing facilities. Expert judgment will be utilized as a part of this determination.

\section{Metrics: Dollars (Applies to site and process)}

\section{Criterion 6. Timeliness}

The goal is to act in an urgent manner for disposition ["...by far the most important statement the $U$. S. can make about its determination to permanently dispose of plutonium from its dismantled nuclear weapons is to do so at the earliest possible date. An early start on disposition is very important to the credibility of the process and to gaining international confidence in the program." Secretary of Energy Advisory Board, September 26, 1996.] Urgent action reduces risks of theft or diversion of weapons-usable material and sends a positive signal to Russia and to the international community regarding disarmament.

Factors to be considered when applying this criterion are:

A. Time to Start Disposition/Time to Open Facility: The time required to start disposition is one measure of timeliness. Preferred options show progress sooner.

Metrics for Site: Date of or time to significant initiation [not token, e.g., "full scale demonstration."] (Applies to site) 
B. Time to Complete: The time required to complete disposition is a measure of timeliness. Options that would complete disposition or storage transition sooner were preferred. For options that achieve a proliferation-resistant waste form (e.g., spent fuel, immobilization with radionuclides) that is ultimately slated for a high-level waste repository, the "time to complete" is the time to achieve the proliferation-resistant waste form, which would be stored pending repository disposal.

Metrics for Site: Date of or time to completion (Applies to site)

C. Schedule Certainty: Schedule certainty refers to the level of confidence regarding the forecast schedule of an option and the actual schedule that would be realized if the option was selected. Schedule estimates must be based upon assumptions and approximations and may be in error. Schedule certainty was lower for those technology options that are in the research or development stage and higher for mature technologies and/or existing facilities.

\section{Metrics for Site: Delta time (Applies to site)}

D. Condition and Reliability of Facilities and Infrastructure (Applies to site) Initiation of new processing activities in existing DOE facilities will likely require upgrades. Most of the processing facilities in the nuclear weapons complex are either in standby status or inoperative. This factor assesses the readiness of existing facilities to support the various options under consideration, and how likely it is that these facilities would remain viable for the duration of the variant's process time scale (Probably 10 years).

Metrics for Site: Time and cost to upgrade for the variant.

Metrics for Process and Form: Not a process and form discriminator.

E. Regulatory/Licensing Requirements: (Applies to site).

New facilities or use of new technologies in old facilities may be more difficult to license or certify for operation. In some cases, this may be site dependent since state and local as well as federal regulations will almost certainly apply. It is recognized that legislation, regulations, and permitting requirements are constantly evolving. This introduces an element of project risk that will be considered in weighing an option.

Metrics for Site: Difficulty in obtaining a license (probably a low discriminator and then only to Greenfield sites). Difficulty in obtaining Defense Nuclear Facility Safety Board (DNFSB) approval (probably a low discriminator). 
Metrics for Process and Form: Difficulty in obtaining a license (probably a low discriminator). Difficulty in obtaining DNFSB approval (probably a low discriminator).

F. Impacts to Existing or Future Missions: This factor assesses the impacts on site and facility selection due to ongoing or already planned missions that would affect the attractiveness of a site or facility. Should there be a potential conflict, the effect on relocating the plutonium immobilization mission or the conflicting mission must be taken into consideration. In addition, the effect on site staff availability, infrastructure support, contractor, and field office support must be gauged.

Metrics: Time/Schedule and possibly costs if relocation is necessary (Applies to site, process, and form)

\section{Criterion 7. Fostering Progress and Cooperation with Russia and Other Countries}

In view of current political and economic instability in Russia, it is essential that disposition activities in the U.S. set appropriate standards and promote timely implementation of secure monitoring regimes and ultimate disposition of nuclear materials in Russia and other countries. ["Prompt agreement with the Russians on disposition schedules is key to national security and arms reduction objectives and will contribute significantly to an early start." Secretary of Energy Advisory Board Task Force, September 26, 1996] An important element of the U.S. disposition program is to work jointly with Russia to study issues and develop solutions that are appropriate for each country. Agreements for secure, safeguarded management and disposition of fissile materials from dismantled nuclear weapons could also help make clear that the nuclear powers are fulfilling their disarmament obligations under Article VI of the Nonproliferation Treaty.

The factors listed below identify the features of disposition options that would lead to a more secure status of weapons-usable nuclear material in other countries.

Factors to be considered when applying this criterion are:

A. Appropriateness as International Standard: The goal is to implement immobilization standards that are jointly developed to achieve similar results in Russia or other countries. Analysis of options must consider their adequacy if applied by other countries. This requires assessments of threat scenarios in other countries, and of how various immobilization options would perform under these scenarios. For a standard to be appropriate, a commensurately low risk of the material being used in weapons (either by the host nation or any other group) must be achieved. (Applies to process and form) 
Metrics for Site: Not a site discriminator.

Metrics for Process and Form: Not a discriminator.

B. Leverage Provided for International Negotiations: The goal is to provide the technical basis for negotiation of bilateral or multilateral-reductions in inventories of weapons-usable fissile materials. This requires consideration of the technical, economic, and policy contexts associated with implementation of options in Russia or other countries. (Applies to form)

Metrics for Site: Not a site discriminator.

Metrics for Process and Form: Not a discriminator.

C. Transparency: It is desirable that disposition activities in the U.S., Russia, and other declared nuclear states be observable by and provide assurances that weapons stockpiles are being reduced. Assessments are based on availability of procedures and technologies for observing fissile material processing and material accounting systems. Consideration of the difficulty to reverse the disposition process in a clandestine fashion are captured in Criterion 1 and by the Host Nation in Criterion 2. (Applies to site, process, and form)

Metrics for Site: Not a site discriminator.

Metrics for Process and Form: Not a discriminator.

\section{Criterion 8. Public and Institutional Acceptance}

The goal is to select immobilization alternatives that are acceptable to the public and cognizant government agencies. It is anticipated that each option will incur some amount of opposition from various governmental agencies, public interest groups, or individuals. An option that is generally acceptable is preferred.

Factors to be considered when applying this criterion are:

A. Ability to Create a Sustainable Consensus: This factor considered the ability to generate and maintain a broad constituency for a particular immobilization option. Changes in governmental bodies will occur throughout the implementation time period. Public dissemination of pertinent information explaining the reasoning behind decisions contribute to creating a sustainable consensus. (Applies to site, process, and form)

Metrics for Site: Time estimated as a function of the number of groups with which the option would have to deal.

Metrics for Process and Form: Not a discriminator. 
B. Socioeconomic Impacts: Positive socioeconomic impacts include an increase in the tax base for local governments or employment base for citizens where facilities are being constructed or staffed. Negative socioeconomic impacts include disruption of a local community due to increased traffic, denial of land use for other purposes, and the boom-bust economic cycle associated with construction or site abandonment. (Applies to site, process, and form)

Metrics for Site: Believed to be either low-level or not a site discriminator.

Metrics for Process and Form: Not a discriminator.

C. Policy-Statute Compatibility: One measure of the potential for gaining approval is the degree to which selection of an option is compatible with existing policies and statutes. The reed for significant legislative or regulatory changes may imply an incompatibility with current public and institutional interests.

Metrics for Site: Not a site discriminator.

Metrics for Process and Form: Believed to be either low-level or not a discriminator. There is a potential risk that the selection of a waste form or a site or a combination could face public opposition. This possibility may occur, for instance, when one waste form is selected to be produced at a site where another form has been selected for all other waste, and the decision to do so is part of a consent agreement with the affected public and regulators. Based on past experience, time delays could result from prolonged negotiations and/or lawsuits that could, in the worst case, lead to rejection of the waste form or site. While this possibility exists, the evaluation of this programmatic risk is outside the scope of this ranking activity for waste form and site selection. However, it needs to be considered as the selection process proceeds. (Applies to site, process, and form)

\section{Criterion 9. Additional Benefits}

A number of options proposed for immobilization may have potential benefits to the government, the commercial sector, and the public in general. These potential additional benefits will be considered when evaluating options as a positive factor. However, a lack of additional benefits will not be a negative factor.

Factors to be considered when applying this criterion are:

A. Contributes to National Initiatives: Some options could benefit other government missions through the sharing of costs and other burdens with other Department of Energy or Department of Defense missions or with other government agencies. (Applies to process and form) 
UCRL-ID-127320

Metrics for Site: Not a site discriminator.

Metrics for Process and Form: Not a discriminator. 
